\title{
'All These Like Little Name Things': A Comparative Study of Language Teachers' Explicit Knowledge of Grammar and Grammatical Terminology
}

\section{Stephen Andrews}

Department of Curriculum Studies, University of Hong Kong, Pokfulam Road, Hong Kong

An in-depth investigation is currently being conducted into the metalinguistic awareness of a group of practising L2 teachers, all non-native speakers teaching English in Hong Kong secondary schools. The investigation focuses on teacher metalinguistic awareness (TMA) as it relates to grammar. As part of this in-depth study, a test was administered in order to explore the declarative dimension of TMA: the teacher's explicit knowledge of grammar and grammatical terminology. The test was based largely on Alderson et al. (1996), which in turn draws upon Bloor (1986). The present paper reports on the test performance of these serving teachers as an indication of the level and nature of their explicit knowledge of grammar and grammatical terminology. It also compares their performance with that of two groups of prospective teachers of EFL/ESL: one group of native-speakers and the other of non-native speakers. Comparison with the former helps to shed light on the native/non-native issue (see, for example, Medgyes, 1994) as it relates to explicit knowledge of grammar, while comparison with the latter offers some indication of the effects of post-secondary education and teaching experience upon such knowledge.

\section{Introduction}

In recent years, amid the wealth of attention which has been paid to the language awareness/'knowledge about language' of learners, especially children, there has been a gradual awakening of research interest, mainly in the UK, into the language awareness of teachers of both L1 and L2 (see, for example, Brumfit, 1988; Chandler et al., 1988, Mitchell \& Hooper, 1991; Wray, 1993; Mitchell et al., 1994, Andrews, 1994a, b; McNeill, 1994, 1996; Williamson \& Hardman, 1995; Brumfit \& Mitchell, 1995; Brumfit et al., 1996). In Hong Kong, where there is considerable public concern about standards of language teaching, the language awareness of teachers has become something of a preoccupation in official circles. Hong Kong Education Commission Report No.6, ${ }^{1}$ for example, recommends introducing 'benchmark' qualifications for all language teachers (L1 and L2) in Hong Kong schools, with language awareness as one of the 'competencies' to be benchmarked (ECR6, 1995). As with much discussion of language awareness, however, it is less than clear precisely what meaning the Commission attaches to the phrase.

The present study is concerned with the language awareness of L2 teachers specifically. However, the term teacher metalinguistic awareness, or TMA (see, for example, Andrews, 1997) is adopted in preference to teacher language awareness in the present paper, for reasons outlined below. Although the scope of such 
awareness potentially extends to all areas of language, the focus of the present study is on grammar.

\section{Teacher Metalinguistic Awareness (TMA)}

The use of the term metalinguistic is not intended to imply a model of teacher language awareness which is limited to an awareness of metalanguage - what Ellis (1994) calls 'metalingual knowledge' and defines as '... knowledge of the technical terminology needed to describe language' (1994: 714). There is also no intention to suggest a view that TMA is synonymous with explicit knowledge about language.

Explicit knowledge about language (the declarative dimension of TMA) is clearly an important part of any L2 teacher's language awareness, defined by Thornbury as '... the knowledge that teachers have of the underlying systems of the language that enables them to teach effectively' (Thornbury, 1997: x). Also, as Alderson et al. (1996) point out '... it would appear that whatever explicit knowledge consists of, it must include metalanguage, and this metalanguage must include words for grammatical categories and functions' (Alderson et al., 1996:2).

However, there is more to teacher language awareness than just explicit knowledge about language systems and of the terminology used for labelling linguistic features. As the second part of Thornbury's definition makes clear, the knowledge-base of the L2 teacher differs qualitatively from the explicit knowledge about language that may be '... exhibited by any competent user of a language who consciously manipulates that language in order to achieve specific communicative purposes' (Andrews, 1997: 149). In the case of the teacher, this explicit knowledge also feeds into her professional practices, potentially exerting a powerful influence upon her ability to teach effectively. It feeds into professional practices by being reflected upon, and arguably it is the quality of these reflections as least as much as the depth or extent of any teacher's explicit knowledge which can have the greatest impact on the teaching/learning process. The use of the term metalinguistic awareness is therefore intended to underline the importance of the teacher's reflections upon her explicit knowledge about language - the metacognitive dimension of language awareness - and also to emphasise the significance of the interrelationship between the declarative and procedural dimensions of teacher language awareness, i.e. between the knowledge-base itself and how that knowledge is drawn upon and applied in the course of professional activity.

Although this justification of the term teacher metalinguistic awareness focuses on the reflective and procedural aspects of TMA, this is not to underestimate the importance of the declarative dimension: the language systems knowledge-base of the L2 teacher. It is clear that explicit knowledge about language is a necessary part of TMA: what is being argued above is that the possession of such knowledge is not in itself sufficient to turn someone into a metalinguistically aware teacher. Given, however, that explicit knowledge about language must form the basis of any L2 teacher's metalinguistic awareness, it is of obvious importance that, in trying to gain a better understanding of TMA, we should investigate the nature and extent of such knowledge. The small-scale study described in the 
present paper attempts to shed light on this issue with specific reference to teachers' explicit knowledge of grammar and grammatical terminology.

\section{Background to the Present Study}

The starting-point for the research reported in this paper was an in-depth study of a group of practising non-native-speaker (NNS) L2 teachers, focusing on TMA as it relates to grammar. One part of that on-going study attempts to investigate the level and nature of the subjects' explicit knowledge of grammar and grammatical terminology. The present study seeks to extend that investigation by comparing the explicit knowledge of grammar and grammatical terminology of the NNS practising L2 teacher group with that of three other groups: one group of NNS prospective L2 teachers, and two groups of native-speaker (NS) prospective L2 teachers with different tertiary study backgrounds, one English Studies and the other Modern Languages.

As part of the in-depth study an attempt is also being made to explore potential influences upon the development of an individual teacher's metalinguistic awareness, bearing in mind the conclusions drawn in Andrews (1994b) that each teacher '... is an amalgam of different characteristics and the product of a range of linguistic and educational experiences, any of which, singly or in combination, may have had some impact upon that individual's grammatical knowledge and awareness' (Andrews, 1994b: 519). Two of the potential influences explored in the in-depth study are subject-matter knowledge and teaching experience.

There has been considerable research interest in the past 15 years in the importance of teachers' subject-matter knowledge (see, for example, Hashweh, 1987, and the papers in Brophy, 1991), especially since Shulman's (1986) call for educational researchers to search for the 'missing paradigm' in research on teaching: subject-matter (Carlsen, 1991: 115). The role of experience has also been examined in a variety of studies of expertise, both in general and with specific reference to teaching (see, for example, Glaser \& Chi, 1988; Borko \& Livingston, 1989; Leinhardt, 1989). However, the link between experience and expertise is clearly not direct. As Tsui (forthcoming) points out: 'While experience is undoubtedly a crucial factor, it will only contribute to expertise if practitioners are capable of learning from it' (Tsui, in press).

There is no attempt in the present study to explore the nature of the relationship between subject-matter knowledge, experience, and what L2 teachers actually do in their classrooms. It was hoped, however, that the study might shed some light on how variations in L2 teachers' explicit knowledge of grammar and grammatical terminology (which might be considered as part of their subject-matter knowledge) related to their tertiary study background and teaching experience. At the same time, it was hoped that the study might provide useful information about a potentially important influence on TMA which is not investigated in the in-depth study: one's language background as a NS or NNS L2 teacher.

\section{The native-speaker/non-native-speaker teacher issue}

Any comparison between NS and NNS teachers has to acknowledge the inherent difficulties in providing a satisfactory answer to the controversial ques- 
tion 'What is a native-speaker?' It is beyond the scope of the present paper to explore this vexed issue. For the purposes of this study subjects were assigned to the category of NS or NNS simply according to their response to the question 'What is your first language (i.e. mother tongue)?' NNSs were also asked 'Is either of your parents a native speaker of English?' All the NNS participants in the present study answered in the negative. No attempt was made to carry out a more detailed investigation of the language backgrounds and the extent of the bilingualism within each of the four groups.

A comparison of the sort envisaged in the present study is made in the belief that, as Medgyes argues (Medgyes, 1994), it is not a case of NNS teachers necessarily being less efficient, but rather that NS and NNS teachers have different strengths. NS teachers are likely, for obvious reasons, to be more proficient users of the language they teach, but in comparison with NNS teachers their explicit knowledge of grammar and grammatical terminology may be seriously deficient. If, as suggested earlier, such knowledge is an essential part of TMA, then it could be argued that teachers lacking such knowledge may place their students at a severe disadvantage.

Andrews (1996) shed interesting light on some of the difficulties NS teachers can have with grammar and grammatical terminology. In a replication of Palfreyman's (1993) study, five pairs of prospective L2 teachers (four NNS pairs and one NS pair) were asked to discuss how they would plan a lesson on the Present Perfect for a Secondary Form 3 class. ${ }^{2}$ Each pair had a grammar book (Leech, 1985) to refer to during their discussions, which were videotaped and transcribed for analysis.

The approaches of the five pairs revealed a number of contrasts. With the NNSs, for example, the two pairs with no teaching experience tended to focus very much on issues of form and function, while the two pairs who had some classroom experience were instead much more concerned with methodology. All four pairs of NNSs, however, could talk quite knowledgeably and confidently about the Present Perfect.

The performance of the two NSs, K and M, was in marked contrast with all four of the NNS pairs. K and M were very aware of their own lack of explicit knowledge:

K: [looking at book] I don't think I'd actually be able to teach this ... Being serious cos I don't really understand it enough myself.

(Andrews, 1996: 203)

As a result, they spent most of the discussion trying to sort out their own understanding of what the Present Perfect was, so that, for example, half an hour into the discussion, the following exchange took place:

M: Well I probably learned this when I was doing French ... [looking at book with puzzled expression]

K: A-level ... there's no way we learned the Present Perfect in GCSE

M: I think we might have done

K: I don't think we did ... I don't I don't think I've ever heard of it in my life [laughs] 
M: I think we might have done ... [looking at book] ... hang on ... of course you have...

K: Or have we done the wrong one? [laughs]

M: Oh I'm going to say something that's going to sound so stupid

K: Go on ... say it

M: [looking at book] This is the same as the Perfect tense in French ... This is the Perfect tense

K: Is it? [laughs]

M: ... Past tense ... yeah ... je suis allée ... I have been ... or I went ... no it's not actually ... the Present no ... in French it's something different ... (Andrews, 1996: 205-206)

Such exchanges as they had about how to teach the Present Perfect focused mainly on the extent to which the explicit teaching of grammar and grammatical terminology was a good thing:

M: $\quad \ldots$ I'd do the Present Perfect forms ...

K: Yeah I'd do that but I don't know whether I'd tell them 'This is the negative form' 'This is the negative question' ... cos that's just ... well just all confusing ...

M: Yeah but how else ... would you say it?

K: ... I'd say ... well I don't know ... I'd say you can use the Present Perfect if you're wanting to ask a question

M: Yeah ... which is the question ...

K: Yeah but it's not giving them a name for it ... cos that's just gonna confuse them ... what I'm saying is that I wouldn't give them all these like little name things ... cos it'll just get too confusing

(Andrews, 1996: 206)

This was, of course, only one pair of NSs, who in this case had not had the benefit of either tertiary education or training. They were 'gap year' students, between school and university, who were working in Hong Kong as English Language Teaching Assistants (ELTAs) giving conversation classes in local secondary schools. The present study attempts to overcome the sample size problem of the earlier study by exploring the explicit knowledge of grammar and grammatical terminology of twenty NSs, divided into two groups.

\section{The Study}

\section{Aims}

The study was designed to shed light on the nature and extent of the explicit knowledge of grammar and grammatical terminology of four types of teacher or prospective teacher:

(1) NNS L2 teachers (NNS Ts);

(2) NNS prospective L2 teachers (NNS pre-Ts);

(3) NS prospective L2 teachers with a tertiary background of English Studies (NS pre-Ts Eng);

(4) NS prospective L2 teachers with a tertiary background of Modern Language Studies (NS pre-Ts ML). 
Comparison between the two NNS groups was intended to test the following hypothesis:

(1) The explicit knowledge of grammar and grammatical terminology of teachers with classroom experience is significantly greater than that of prospective teachers.

The addition of two NS groups was designed to facilitate testing of two further hypotheses:

(2) The explicit knowledge of grammar and grammatical terminology of non-native-speakers is significantly greater than that of native-speakers; and

(3) The explicit knowledge of grammar and grammatical terminology of native-speakers with a tertiary background of Modern Language Studies is significantly greater than that of native-speakers with a tertiary background of English Studies (as suggested by trainers of native-speaker EFL teachers in Andrews, 1994b).

\section{Subjects}

As indicated above, four groups of subjects participated in the study. The NNS Ts were 20 serving teachers of English in Hong Kong secondary schools. All of them were graduates, of a range of subjects and from a variety of institutions, both in Hong Kong and overseas. They had an average of two years' full-time teaching experience, and no previous professional training as teachers. At the time the study was conducted, they were about to begin a two-year part-time postgraduate certificate in education course as English Majors. There were also 20 NNS pre-Ts, in this case prospective teachers of English in Hong Kong secondary schools. They were all school-leavers beginning a four-year full-time undergraduate course in English Language Education. The other two groups together comprised 20 subjects, all NS prospective teachers following a one-year full-time postgraduate certificate in education course in the UK, and all about to begin a Minor elective in TEFL/TESL. The ten NS pre-Ts Eng were all graduates in English Studies, while the ten NS pre-Ts ML were graduates in Modern Languages.

The process of sampling was a mixture of random and purposive. Each of the groups apart from the NNS teachers was a random sample: the NNS pre-teachers were a complete cohort beginning the English Language Education degree course, while the NS subjects comprised all the native speakers opting for the TEFL/TESL elective in the year that the study was conducted. In the case of the NNS teachers, the sampling was initially random: all 187 English Major applicants for the postgraduate certificate in education course in a given year performed a range of testing tasks, and supplied information about their study and professional background. The selection of a group of 20 (from the 187) for in-depth study was purposive, with the aim of achieving a broad similarity between the groups of 20 and 187 in the following respects: mean and range of performance on the testing tasks, gender, location of tertiary education (Hong Kong or overseas), relevance of degree, and years of teaching experience.

Before describing the procedures, it is important to note that this was only a 
small-scale study. Given the size of the groups, one would not wish to generalise too much when considering the results. It is also clear that the groups were not perfectly matched. Although the NNS teachers and the two NS pre-teacher groups were all beginning a postgraduate training course, the NNS group were already serving teachers, while the NS groups were not (though some did in fact have TEFL experience).

\section{Instrument}

Subjects were given a 60-item test largely based on that devised by Alderson $e t$ al. (see, for example, Alderson et al., 1996), which itself drew heavily upon an earlier test designed by Bloor (see, for example, Bloor, 1986). There were a variety of reasons for adopting the Alderson et al. test as the basis for the test of explicit knowledge about language. First, it had already been carefully trialled as part of Alderson et al's own study. Second, it had been shown to measure a factor of language ability which was independent from language competence/communicative competence (Alderson et al., 1996: 11-12). Third, it appeared to have construct validity as a measure of the declarative dimension of TMA in that it was potentially revealing about both knowledge of metalanguage and also the ability to state grammatical rules (with or without the use of metalinguistic terminology). The test was adapted for two reasons: first, the Alderson et al. test included exercises in French, which were, for obvious reasons, inappropriate for the majority of subjects in the present study, and second, it was felt that the test might be improved by the addition of a task intended to shed light on subjects' ability to produce appropriate metalinguistic terms. Following the adaptations it was thought that the test content was equally suitable for use in the UK (where the test originated) and in Hong Kong (home of the NNS subjects).

The test consisted of four sections, each focusing on a different facet of explicit knowledge of grammar and grammatical terminology. Section 1 tested subjects' ability to recognise metalanguage. This section of the test (from Alderson et al., 1996, and originally taken from Bloor, 1986) was made up of two tasks with a total of eighteen items. The first task provided subjects with a sentence and fourteen different grammatical categories (for instance, countable noun, preposition, finite verb). Subjects had to select one example of each grammaticalitem from the sentence. The second task in the first section comprised four items, each consisting of a sentence and a grammatical function (for example, direct object). Subjects had to underline the word(s) in the sentence which performed the particular function. Section 2 focused on the subjects' ability to produce appropriate metalinguistic terms. This section was designed specifically for this test and consisted of a single twelve-item task. Each item consisted of a sentence in which a word or phrase was underlined. Subjects were asked to provide a grammatical term which would precisely describe each of the underlined words/phrases. Section 3 tested subjects' ability to identify and correct errors, while Section 4 examined their ability to explain grammatical rules. Sections 3 and 4 (from Alderson et al., 1996) each consisted of 15 items. These two sections were combined in the actual test, so that for each of 15 sentences subjects were asked (a) to rewrite the faulty part of the sentence correctly, and (b) to explain the grammatical rule thought to be broken. Section 3 - the error identification/correction task - was included in the test because it formed part of the 
Alderson et al. test, and because of its importance in providing a stimulus for each of the items in Section 4. It differs from the other sections of the test, however, in that it is primarily a test of language proficiency, one on which NSs might be expected to score close to $100 \%$, rather than being a test of explicit knowledge of grammar and grammatical terminology. For this reason, discussion of the results and subjects' performance on the test focuses mainly on the other three sections.

\section{Procedures}

For the purposes of administration, the content of the test was organised into two parts. Part 1 consisted of Sections 1 and 2, while Part 2 comprised Sections 3 and 4 . Ten minutes were assigned to each part of the test. After ten minutes subjects had to move on to Part 2, whether or not they had finished Part 1.

All the subjects sat the test under similar test conditions, under careful supervision and without the opportunity to consult reference materials or each other. The two groups of NNS subjects completed the test on separate occasions in the presence of the researcher. The NS subjects were tested in a single administration under the supervision of their course tutor, following the instructions of the researcher.

\section{Scoring}

The test was examiner-marked using a mark-scheme modified by the researcher from that devised by Alderson et al. On each item it was possible to score a maximum of two marks. For most of the items in Section 2 and all the items in Section 4 it was also possible to gain 1 mark for a partially correct answer. For example, in Section 2 item 5, where subjects were required to provide a full grammatical description for the word 'very' in the sentence 'You play tennis very well', the response 'adverb of degree' earned two marks, while 'adverb' alone (or 'degree' alone) earned only one mark. ${ }^{3}$ A similar marking system applied throughout Section 4. For instance, in item 3, when explaining the correction of the sentence 'Every day I am making good resolutions' to read ‘Every day I make good resolutions', a response such as 'Simple present tense should be used when we talk about a habitual action' gained the full two marks. 'Present tense is used when referring to the time word - every day' earned one mark, while 'Tense of the verb should agree with the time given' was given zero marks.

\section{Results: An overview}

Table 1 shows the detailed results for the four groups, starting with the means and standard deviations for the overall test, and then showing the figures for each of the four sections of the test. Results throughout the paper are reported as percentages, for the whole test and for each section.

The bar charts below may help to highlight some of the patterns emerging from an analysis of the results. Figure 1, for example, gives a very clear illustration of the widely contrasting levels of performance of the NNS T and the NS pre-T Eng groups, with the other two groups somewhat closer together in the middle. As can be seen from the bar chart, the already marked contrast between the performances of those two groups becomes even more marked if the error identification/correction task is removed from the analysis, on the grounds mentioned earlier: that it is primarily a test of language proficiency, and there- 
Table 1 Mean scores (\%) for overall test and each section

\begin{tabular}{|l|c|c|c|c|c|c|c|c|c|c|c|c|}
\hline & \multicolumn{3}{|c|}{$\begin{array}{c}\text { NNS Ts } \\
n=20\end{array}$} & \multicolumn{3}{c|}{$\begin{array}{c}\text { NNS pre-Ts } \\
n=20\end{array}$} & \multicolumn{3}{c|}{$\begin{array}{c}\text { NNS pre-Ts Eng } \\
n=10\end{array}$} & \multicolumn{3}{c|}{$\begin{array}{c}\text { NNS pre-Ts ML } \\
n=10\end{array}$} \\
\hline & Mean & SD & Range & Mean & SD & Range & Mean & SD & Range & Mean & SD & Range \\
\hline $\begin{array}{l}\text { Metalanguage } \\
\text { recognition } \\
(18 \text { items) }\end{array}$ & 82.76 & 8.99 & 33.30 & 71.94 & 12.93 & 50.00 & 50.61 & 18.65 & 60.50 & 76.12 & 9.46 & 27.80 \\
$\begin{array}{l}\text { Metalanguage } \\
\text { production } \\
(12 \text { items })\end{array}$ & 65.84 & 17.08 & 62.50 & 48.76 & 16.84 & 62.50 & 14.34 & 15.44 & 41.70 & 33.39 & 14.02 & 41.70 \\
$\begin{array}{l}\text { Error } \\
\text { correction } \\
(15 \text { items })\end{array}$ & 87.01 & 10.48 & 46.70 & 76.67 & 12.53 & 40.00 & 85.34 & 24.09 & 73.30 & 96.00 & 10.51 & 33.30 \\
$\begin{array}{l}\text { Rules and } \\
\text { explanations } \\
\text { (15 items }\end{array}$ & 42.49 & 17.08 & 73.30 & 22.32 & 9.55 & 36.60 & 11.66 & 11.57 & 33.30 & 27.34 & 15.22 & 50.00 \\
\hline
\end{tabular}

fore favours the NS subjects. In fact, the only NS subjects to score below $100 \%$ on this task did so because they did not complete it. With this adjustment, shown in Figure 1 as the right-hand bar for each group, the mean score for the NS pre-Ts Eng falls to less than half that for the NNS teachers, while the mean performance of the second NS group (the NS pre-Ts ML) drops to slightly below that of the other NNS group (the NNS pre-Ts).

Although the scores for the NNS pre-Ts and the NS pre-Ts ML are quite close together, the overall pattern of results is consistent with all three hypotheses. The group with teaching experience performed markedly better than the groups with no classroom experience (Hypothesis 1), the NNS subjects (particularly the NNS Ts) generally performed better than the NS subjects (Hypothesis 2), and the NS pre-Ts ML outperformed the NS pre-Ts Eng (Hypothesis 3). This is discussed in more detail later in the paper.

Figure 2 shows the performance patterns of the four groups on all four sections of the test. In comparing performance on the first two sections of the test, those concerned with the recognition and production of metalinguistic terms (shown as the middle two columns for each group in Figure 2), it is interesting to note that while all the groups scored more highly on the former task than the latter, it was the two NS groups which showed the biggest contrast in the level of
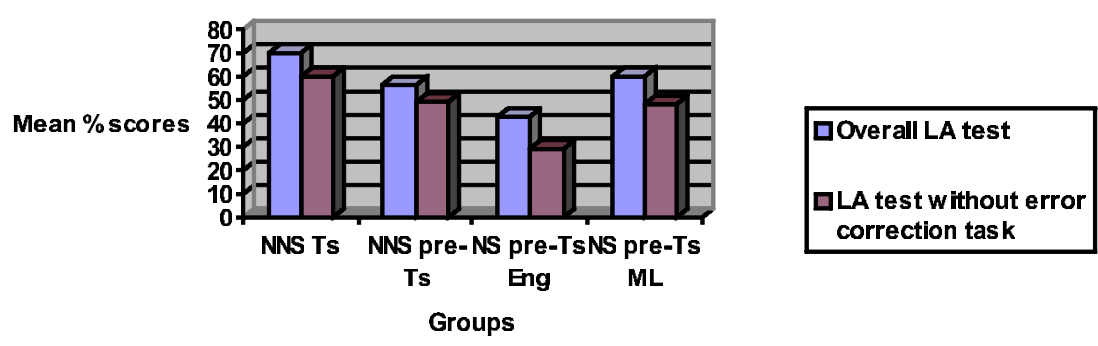

Figure 1 Mean total scores on LA test with and without error correction task 

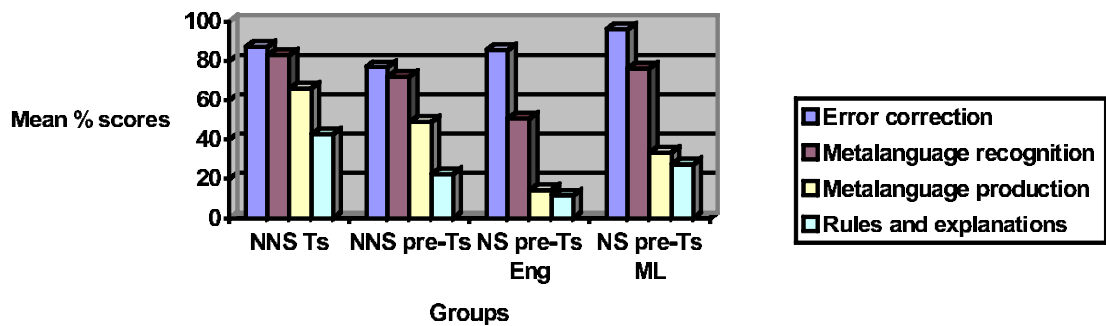

Groups

Figure 2 Mean scores for each section of LA test

their performance on the two tasks. In each case, their mean score on the test of metalanguage production was less than half their mean score for metalanguage recognition. This meant that while the NS pre-Ts ML outperformed the NNS pre-Ts on the recognition task, the order was reversed on the measure of production. The most noteworthy feature of performance on the rules and explanations task would seem to be the weak performance of all four groups. The pattern of performance reflects that already seen for the overall test and for the metalanguage recognition task, but on this occasion even the NNS Ts achieved a mean score of only $42.49 \%$, while the NS pre-Ts Eng could only manage a lamentably weak $11.66 \%$.

One noteworthy feature of performance on the test as a whole, shown in Figure 2, is that each group had a similar pattern of results across the four sections of the test. For each group, the error correction task proved the easiest, followed by the metalanguage recognition task, the metalanguage production task, and the rules and explanations task. The most plausible explanation for this pattern would seem to be that each successive task in that sequence places a greater cognitive burden upon a subject's TMA than the one before. The error correction task, as discussed above, is primarily a test of language proficiency, rather than of explicit knowledge about language. The metalanguage recognition tasks, whilst testing a subject's explicit knowledge about language, are cognitively less demanding than the two subsequent tasks in that subjects are not required to supply any terms, but only to match given terms to examples. The metalanguage production task adds to the cognitive burden by requiring subjects to look within their own mental store of explicit knowledge about language in order to seek the appropriate metalinguistic terms to describe a language item, while the rules and explanations task increases the cognitive demand still further by requiring subjects to (1) reflect upon a grammatical error which they have corrected, (2) make explicit the rule which has been broken, and (3) employ appropriate metalanguage in order to explain the rule.

The mean scores on four measures (the overall test and each of the three sections focusing on explicit knowledge of grammar and grammatical terminology) were subjected to a one way ANOVA. This confirmed that there was significant variance among the four groups. The $F$ values for the overall test, the metalanguage recognition measure, the metalanguage production measure, and 
the rules and explanations test were $19.479,15.187,24.69$ and 13.273 respectively. In each case, the $p$ value was $<0.00005$.

A post-hoc test (Tukey-HSD with a significance level 0.050) revealed that the great majority of performance differences between the four groups were statistically significant. In particular, the performance of the NNS Ts was shown to be significantly different from that of each of the other three groups on the overall test and on all three sub-tests except the metalanguage recognition measure, where the difference between the NNS Ts and the NS pre-Ts ML was not statistically significant. The performance of the NS pre-Ts Eng was significantly different from that of each of the other three groups on both the overall test and the metalanguage recognition measure, while on the test of metalanguage production it was significantly different from the performance of the NNS pre-Ts as well as the NNS Ts. None of the differences between the NNS pre-Ts and the NS pre-Ts ML was shown to be statistically significant.

\section{Results: Task by task commentary}

A more detailed examination of the performance of the four groups on the different components of the test reveals some interesting points of comparison and contrast. As described earlier, the first section of the test, the measure of metalanguage recognition, consisted of two tasks. The rubric for the first read as follows:

From the sentence below select one example of the grammatical item requested and write it in the space provided:

Materials are delivered to the factory by a supplier, who usually has no technical knowledge, but who happens to have the right contacts.

Table 2 shows the level of performance on some of the individual items in this task, revealing contrasts which were mirrored in the test as a whole. The table also indicates some of the specific gaps in explicit knowledge, which became still more apparent in later parts of the test.

Table 2 Performance on sample items from Section 1 task 1

\begin{tabular}{|l|c|c|c|c|}
\hline \multirow{2}{*}{} & \multicolumn{4}{|c|}{ Percentage of correct responses } \\
\cline { 2 - 5 } & NNS Ts & NNS pre-Ts & NS pre-Ts Eng & NS pre-Ts ML \\
\hline Passive verb & 95 & 100 & 30 & 70 \\
\hline Preposition & 100 & 95 & 30 & 80 \\
\hline Finite verb & 80 & 75 & 40 & 40 \\
\hline
\end{tabular}

The second task in the first section tested subjects' ability to identify grammatical functions in four simple sentences. In the second of these, 'Joe had nowhere to shelter', subjects had to underline the predicate. Not one of the NS subjects could identify the predicate correctly, while only $17.5 \%$ of the NNS subjects were able to do so. The performance of the NNS subjects on this item is not surprising, given that the term 'predicate' does not usually appear in any secondary English textbooks used in Hong Kong secondary schools. As a result, very few of either the NNS pre-Ts or NNS Ts would be likely to have encountered it. The perfor- 
mance of the NS subjects would suggest that few, if any, had previously encountered the term either.

The fourth item in the second task required subjects to identify the indirect object in the sentence 'The woman gave him some money'. As Table 3 shows, this produced a somewhat anomalous pattern of correct responses.

Table 3 Performance on sample items from section 1 task 2

\begin{tabular}{|c|c|c|c|}
\hline \multicolumn{4}{|c|}{ Percentage of correct responses } \\
\hline NNS Ts & NNS pre-Ts & NS pre-Ts Eng & NS pre-Ts ML \\
\hline 40 & 35 & 40 & 90 \\
\hline
\end{tabular}

In pondering the reasons for this anomaly, it is tempting to speculate that this item proved rather easier for the NS pre-Ts ML than for any of the other groups because of the amount of time the former might have spent distinguishing and labelling different forms of personal pronoun in their previous studies of languages such as German.

Section 2 of the test focused on metalanguage production. The rubric for this particular task was as follows:

What grammatical terms would you use to describe the items underlined in each of the twelve sentences below? For each item provide a full description.

Table 4 shows the pattern of response for three of the items, a pattern which characterised this section as a whole, with the NS subjects performing very poorly in comparison with the two NNS groups.

Table 4 Performance on sample items from Section 2

\begin{tabular}{|c|c|c|c|c|}
\hline & \multicolumn{4}{|c|}{ Percentage of correct responses } \\
\hline & NNS Ts & NNS pre-Ts & $\begin{array}{c}\text { NS pre-Ts } \\
\text { Eng }\end{array}$ & $\begin{array}{l}\text { NS pre-Ts } \\
M L\end{array}$ \\
\hline (1) 'It's a lovely day, isn't it?' & 80 & 70 & 0 & 15 \\
\hline $\begin{array}{c}\text { (6) 'I look forward to receiving } \\
\text { a reply to my letter.' }\end{array}$ & 95 & 60 & 10 & 20 \\
\hline $\begin{array}{c}\text { (9) 'Mrs Wong has been living } \\
\text { in that flat for years.' }\end{array}$ & 87.5 & 75 & 5 & 25 \\
\hline
\end{tabular}

One of the twelve items performed somewhat oddly, as Table 5 shows, with the anomaly being the poor performance of the NNS Ts. One might hypothesise from an examination of their incorrect responses that in this instance many NNS T subjects simply produced the label 'adverb' without pausing to analyse the sentence more closely, although this hypothesis does not provide a satisfactory explanation for the comparatively good performance of the NNS pre-Ts and the NS pre-Ts ML.

As an indication of the difficulties many of the NS subjects experienced with this particular task, it may be instructive to look at some of the metalanguage they produced as labels. In the sentence 'Alice fell asleep during the lecture', for example, 'during' was variously described as 'passive verb', 'conjunction', 
Table 5 Performance on sample item from Section 2

\begin{tabular}{|c|c|c|c|c||}
\hline \multirow{2}{*}{} & \multicolumn{4}{|c||}{ Percentage of correct responses } \\
\cline { 2 - 5 } & NNS Ts & NNS pre-Ts & $\begin{array}{c}\text { NS pre-Ts } \\
\text { Eng }\end{array}$ & NS pre-Ts ML \\
\hline (10) 'I'm not feeling very \\
$\begin{array}{c}\text { well today: I have a } \\
\text { terrible headache'. }\end{array}$ & 17.5 & 70 & 20 & 70 \\
\hline
\end{tabular}

'adjective', 'present continuous' and 'present participle'. The verb group 'has been living' (from item 9 above) was similarly mislabelled as 'past participle', 'verb imperfect tense', 'past tense verb', 'present passive', 'pluperfect', 'past perfect', 'past continuous' and 'continuous imperfect'. Meanwhile, 'to be done' in the sentence 'There are still a lot of things to be done' was identified by NS subjects as, among other things, 'conjunction', 'future verb', 'auxiliary verb', 'verb to be past tense', 'future perfect' and 'past perfect'.

The final section of the test required subjects to give rules to explain the nature of the error in each of fifteen sentences. Sample items from this task show (in Table 6) a pattern of performance similar to that already noted on other parts of the test. They also provide a clear, and worrying, illustration of the low level of explicit grammar knowledge exhibited by many subjects, both NS and NNS, in dealing with even quite elementary errors.

Table 6 Performance on sample items from Section 4

\begin{tabular}{|c|c|c|c|c||}
\hline \multirow{2}{*}{} & \multicolumn{4}{|c||}{ Percentage of correct responses } \\
\cline { 2 - 5 } & NNS Ts & NNS pre-Ts & NS pre-Ts Eng & NS pre-Ts ML \\
\hline (1) 'I walk to work very & 82.5 & 40 & 20 & 35 \\
quick'. & 67.5 & 20 & 5 & 35 \\
\hline $\begin{array}{l}\text { (2) 'When her said that, } \\
\text { Jack hit her'. }\end{array}$ & 77.5 & 55 & 30 & 55 \\
\hline $\begin{array}{l}\text { (9) 'I don't like people } \\
\text { which are always } \\
\text { complaining'. }\end{array}$ & & & & \\
\hline
\end{tabular}

\section{Conclusions and Recommendations}

In drawing any conclusions from this particular study, one should bear in mind the caveats mentioned earlier concerning sample size and the imperfect matching of groups. Having said that, there seem to be a number of observations to be made, first in relation to the three hypotheses, and then about the performance of the four groups.

The first point to note is that, as mentioned above, the results are consistent with each of the three hypotheses, although this statement requires some qualification. As far as teaching experience is concerned (Hypothesis 1), the one group where every subject had been teaching for at least two years clearly outperformed the other three groups. This would suggest that teaching experience may indeed have a significant impact upon the development of a teacher's explicit 
knowledge of grammar and grammatical terminology. However, such a statement raises a host of follow-up questions which the present study does not address. For example, is it quantity of teaching experience which is the determining factor, or quality of experience, or both? Also, is the impact of teaching experience influenced in any way by the relevance or otherwise of a subject's previous study experience?

In relation to the NS/NNS issue (Hypothesis 2), the marked difference in performance between the NNS Ts, on the one hand, and the two NS groups, on the other hand, would suggest that in a comparison of NNSs and NSs at a similar stage of their L2 teacher education, the NNSs could be expected to possess a considerably better level of explicit knowledge of grammar and grammatical terminology. At the same time, however, the potential influence of other factors such as experience and subject of tertiary education cannot be overlooked. The fact that the overall performance of the second NNS group (the NNS pre-Ts) was not much better than that of the NS pre-Ts ML would seem to suggest that the experiences associated with being a non-native-speaker are likely to be a potential contributing factor rather than a determining factor in the development of explicit knowledge of grammar and grammatical terminology.

As for the impact of tertiary study background (Hypothesis 3 ), the contrasting levels of performance of the two NS groups appear to suggest that tertiary study background can have a significant influence on explicit knowledge of grammar and grammatical terminology. However, it is important to bear in mind that the comparison involved only two study areas, and only NS prospective teachers with a British educational background. Also, in noting the relatively good performance of those subjects with a Modern Language Studies background, one might speculate that anyone who opts to study MLs at university is likely to have a greater interest in language systems and how they work than those who study other subjects. This might explain why ML graduates performed better than their English Studies counterparts, rather than the mere fact of having followed a degree course in MLs.

If one turns to the quality of performance of the four groups, there are a number of conclusions which might be drawn. First, as far as the main study group, the NNS Ts, is concerned, their relatively high level of language proficiency (as indicated by their performance on the error recognition/correction task) and their relatively good performance in recognising metalanguage were not matched by their ability to produce metalanguage, and especially not by their ability to state/explain a rule which had been broken. Given that the subjects in this group are all serving teachers and that the latter tasks did not involve complex metalanguage or obscure rules of grammar, this is cause for concern, particularly since their classroom practice typically involves rule explanation. ${ }^{4}$

However, whatever reservations one might have about the performance of the NNS Ts, they performed significantly better than both NS pre-T groups, irrespective of the tertiary background of the latter. Such a difference is unlikely to be the result of any positive influence from the NNS Ts' own tertiary education, since this group has a very wide range of tertiary backgrounds, half of them totally irrelevant to TEFL/TESL (including Applied Physics), while the NS pre-Ts have, in theory at least, more relevant tertiary backgrounds. A more likely determining factor would seem to be experience, as mentioned earlier, particu- 
larly in view of the performance of the NNS pre-Ts, whose mean scores were not significantly different from those of the NS pre-Ts ML.

With this second NNS group, those just starting a four-year course to become teachers of EFL/ESL, it is interesting and also worrying to note that, as products of at least 13 years of typically very form-focused teaching of English, they did not perform especially well on a test of explicit grammar knowledge which is not hugely demanding. The relatively low level of this group's explicit knowledge of grammar and grammatical terminology is all the more depressing since it does not appear (on the evidence of post-test observation) to be offset by a compensatory high level of communicative ability, either written or oral.

The difference in the performance of the two NS groups is also noteworthy, especially since it reflects teacher-trainers' impressions, reported in Andrews (1994a) of factors linking positively or negatively with grammatical knowledge/awareness (1994a: 73-74). The performance of the NS pre-Ts Eng on this test was particularly poor. Whilst acknowledging that (1) the subject sample is very small, (2) the label 'English Studies' covers a wide range of very different programmes, and (3) explicit knowledge of grammar and grammatical terminology is only one facet of TMA, which is in turn only one component of the knowledge and skills required of the $\mathrm{L} 2$ teacher, it is nonetheless disturbing that graduates in English Studies (which might be expected to provide a foundation for a career in TEFL/TESL) should display such a lack of explicit knowledge of even basic English grammar.

If one were to make any recommendations based on this small-scale study, there would seem to be potential implications for both research and teacher education. First, as far as research is concerned, there seems to be a clear need for the area of TMA to be investigated much more fully. Advocating a need for such research does not reflect a wish to downplay the importance of the learner, but rather to redress the balance somewhat, and to remind us of the crucial role the teacher plays in relation to the input made available to the learners. As for teacher education, even a small-scale study of this sort seems to underline the importance of including a focus on explicit knowledge of grammar and grammatical terminology for all prospective L2 teachers, regardless of whether they are NSs or NNSs of that language, and regardless of their study background.

In making these recommendations, however, we need to bear in mind the point made in the introduction to this paper, that this sort of explicit knowledge of grammar and grammatical terminology is only one facet of TMA. Both research and teacher education need to broaden the scope of their interest in TMA to include all the language systems, not just grammar, and to incorporate both the declarative and the procedural dimensions of TMA.

\section{Acknowledgements}

I would like to thank Alice Deignan and students of the Universities of Leeds and Hong Kong for their cooperation in providing the data for this study. I would also like to thank Arthur McNeill for his assistance with the statistical analysis, and two anonymous reviewers for their very helpful comments on an earlier version of this paper. 


\section{Correspondence}

Any correspondence should be directed to Stephen Andrews, Department of Curriculum Studies, University of Hong Kong, Pokfulam Road, Hong Kong (sandrews@hkucc.hku.hk).

\section{Notes}

1. The Hong Kong Education Commission is an independent consultative body set up by the Hong Kong Government in 1982 to review the education system and advise on education policy. Since then it has had a major influence on developments in Hong Kong's education system. Report No.6 (1995) was accepted by the Government in March 1996.

2. The context of the study was Hong Kong, where Form 3 is the third year of secondary school (the equivalent of Year 9 in schools in England and Wales). Form 3 students in Hong Kong are typically 14 years old and in their ninth year of studying English.

3. The two exceptions were item 1 , 'It's a lovely day, isn'tit?' and item 3 ,'Alice fell asleep during the lecture'. For these items, the responses (1) 'question tag' and (3) 'preposition' earned two marks, and there were no partially correct answers.

4. Although some rule explanation in Hong Kong secondary schools involves the use of Cantonese, or a mixture of codes, many teachers do use English (wholly or in part) in their explanations, and all textbook explanations are in English with English terminology.

\section{References}

Alderson, J.C., Clapham, C. and Steel, D. (1996) Metalinguistic Knowledge, Language Aptitude and Language Proficiency. CRLE, University of Lancaster Working Papers, 26.

Andrews, S.J. (1994a) The grammatical knowledge/awareness of native-speaker EFL teachers: What the trainers say. In M. Bygate, A. Tonkyn and E. Williams (eds) Grammar and the Language Teacher. Hemel Hempstead: Prentice Hall.

Andrews, S.J. (1994b) The grammatical awareness and knowledge of Hong Kong teachers of English. In N. Bird, P. Falvey, A.B.M. Tsui, D.M. Allison and A. McNeill (eds) Language and Learning. Hong Kong: ILE/Govt. Printer.

Andrews, S.J. (1996) Metalinguistic awareness and lesson planning. In P. Storey, V. Berry, D. Bunton, and P. Hoare (eds) Issues in Language in Education. Hong Kong: Hong Kong Institute of Education.

Andrews, S.J. (1997) Metalinguistic awareness and teacher explanation. Language Awareness 6 (2\&3), 147-161.

Bloor, T. (1986) What do language students know about grammar? British Journal of Language Teaching 24 (3), 157-160.

Borko, H. and Livingston, C. (1989) Cognition and improvisation: Differences in mathematics instruction by expert and novice teachers. American Educational Research Journal 26 (4), 473-498.

Brophy, J. (ed)(1991) Advances in Researchon Teaching (Vol.2). Greenwich, Connecticut: JAI Press.

Brumfit, C.J. (1988) Language in Teacher Education. London: NCLE.

Brumfit, C.J. and Mitchell, R. (1995) Trainee Teachers' Knowledge about Language. CLE, University of Southampton Occasional Papers 33.

Brumfit, C.J., Mitchell, R. and Hooper, J. (1996) 'Grammar', 'language' and classroom practice. In M. Hughes (ed.) Teaching and Learning in Changing Times. Oxford: Blackwell.

Carlsen, W.S. (1991) Subject-matter knowledge and science teaching: A pragmatic perspective. In J. Brophy (ed.) Advances in Research on Teaching (Vol.2) Greenwich, CT: JAI Press.

Chandler, P., Robinson, W.P. and Noyes, P. (1988) The level of linguistic knowledge and awareness among students training to be primary teachers. Language and Education 2 (3), 161-173. 
Education Commission (1995) Education Commission Report No.6 - Enhancing Language Proficiency: A Comprehensive Strategy. Hong Kong: Hong Kong Government.

Ellis, R. (1994) The Study of Second Language Acquisition. Oxford: Oxford University Press.

Glaser, R. and Chi, M.T.H. (1988) 'Overview' In M.T.H. Chi, R. Glaser and M. Farr (eds) The Nature of Expertise. Hillsdale, NJ: Erlbaum.

Hashweh, M.Z. (1987) Effects of subject-matter knowledge in the teaching of biology and physics. Teacher and Teacher Education 3 (2), 109-120.

Leech, G. (1985) An A-Z of English Grammar. London: Edward Arnold.

Leinhardt, G. (1989) A contrast of novice and expert competence in mathematics lessons. In J. Lowyck and C.M. Clark (eds) Teacher Thinking and Professional Action. Louvain: Louvain University Press.

McNeill, A. (1994) Some characteristics of native and non-native speaker teachers of English. In. N. Bird, P. Falvey, A.B.M. Tsui, D. Allison and A. McNeill (eds) Language and Learning. Hong Kong: ILE/Govt. Printer.

McNeill, A. (1996) Vocabulary knowledge profiles: Evidence from Chinese-speaking ESL teachers. Hong Kong Journal of Applied Linguistics 1 (1), 39-63.

Medgyes, P. (1994) The Non-native Teacher. Basingstoke: Macmillan.

Mitchell, R. and Hooper, J. (1991)Teachers' views of language knowledge. In C. James and P. Garrett (eds) Language Awareness in the Classroom. London: Longman.

Mitchell, R., Hooper, J. and Brumfit, C.J. (1994) Final report: 'Knowledge about Language', Language Learning and the National Curriculum. CLE, University of Sourthampton Occasional Papers, 19.

Palfreyman, D. (1993) 'How I got it in my head': Conceptual models of language and learning in native and non-native trainee EFL teachers. Language Awareness 2 (4), 209-223.

Shulman, L. (1986) Paradigms and research programs in the study of teaching: A contemporary perspective. In M.C. Wittrock (ed.) Handbook of Researchon Teaching (3rd edn). New York: Macmillan.

Thornbury, S. (1997) About Language. Cambridge: Cambridge University Press.

Tsui, A.B.M. (forthcoming) Understanding Expertise in Teaching - Case Studies of ESL Teachers. New York: Cambridge University Press.

Williamson, J. and Hardman, F. (1995) Time for refilling the bath?: A study of primary student-teachers' grammatical knowledge. Language and Education 9 (2), 117-134.

Wray, D. (1993) Student-teachers' knowledge and beliefs about language. In N. Bennett and C. Carre (eds) Learning to Teach. London: Routledge. 